\title{
Comportamentos de polidez em sala de aula
}

\author{
Politeness behavior in classroom
}

\author{
Paula Inez Cunha Gomide ${ }^{[a]}$, Ângela Primo ${ }^{[b]}$, Carlos César Petruy ${ }^{[c]}$, Francine Porfirio Ortiz ${ }^{[d]}$, \\ Juliane Muniz ${ }^{[\mathrm{ee}}$, Marilene Gomes de Oliveira ${ }^{[\mathrm{ff}}$, Vera Maria Immich ${ }^{[\mathrm{g}]}$
}

\footnotetext{
${ }^{[a]}$ Doutora em Psicologia (Psicologia Experimental) pela Universidade de São Paulo (USP), professora titular da Faculdade Evangélica do Paraná (FEPAR), professora adjunta da Universidade Tuiuti do Paraná (UTP), Curitiba, PR - Brasil, e-mail: pgomide@onda.com.br

${ }^{\left[{ }^{[b]}\right.}$ Psicóloga, Faculdade Evangélica do Paraná (FEPAR), Curitiba, PR - Brasil, e-mail: angelapprimo@hotmail.com

${ }^{[c]}$ Psicólogo, Faculdade Evangélica do Paraná (FEPAR), Curitiba, PR - Brasil, e-mail: yurtep@yahoo.com.br

${ }^{[d]}$ Psicóloga, Faculdade Evangélica do Paraná (FEPAR) Curitiba, PR - Brasil, e-mail: francine.porfirio@gmail.com

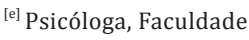
Evangélica do Paraná (FEPAR), Curitiba, PR - Brasil, e-mail: juliane.muniz@yahoo.com.br

${ }^{[\mathrm{f}]}$ Psicóloga, Faculdade Evangélica do Paraná (FEPAR), Curitiba, PR - Brasil, e-mail: marilenego@ibest.com.br

${ }^{\left[{ }^{[g]}\right.}$ Psicóloga, Faculdade Evangélica do Paraná (FEPAR) Curitiba, PR - Brasil, e-mail: veraodair@terra.com.br
}

Recebido: $17 / 08 / 2010$ Received: 08/17/2010

Aprovado: $11 / 05 / 2011$ Approved: 05/11/2011

\section{Resumo}

Autores que estudam o comportamento moral entendem que a polidez é a porta de entrada para as virtudes. Ela não é propriamente uma virtude, mas tem a aparência de uma. Jovens modernos a consideram dispensável, porém estudiosos da moralidade enfatizam que os comportamentos polidos facilitam os relacionamentos humanos, tornando-os mais prazerosos. Como toda virtude, ela é aprendida. Foram observados e registrados comportamentos polidos e impolidos em 56 alunos, de ambos os sexos, em uma sala de aula do ensino fundamental. Os comportamentos estudados foram: cumprimentar, agradecer, pedir licença, desculpar-se e pedir por favor. Os resultados mostraram que a maioria dos participantes, independentemente de sexo, apresentou mais comportamentos impolidos do que polidos ( $t=-6,849 ; p=0,0001)$. Ensinar a importância da polidez para facilitar as relações humanas, no sentido de harmonizá-las, é um desafio para educadores e pais. A sociedade deve desenvolver mecanismos que inibam comportamentos hostis, e a polidez é um destes mecanismos.

Palavras-chave: Polidez. Impolidez. Comportamento moral. Observação de comportamento.

\begin{abstract}
Authors who study moral behavior consider that politeness is the front door to the virtues. It is not properly a virtue, but looks like one. Young people from modern time may consider it expendable, although researches on morality emphasize that polite behaviors make human relationships easier by turning them into something more delightful. As well as all virtues, it may be learned. Polite and impolite behaviors in school classroom of 56 students, of both genders, were observed and registered. The studied behaviors were: greeting, thanking, excusing, apologizing, and saying please. Results have shown that most of the participant kids, irrespective of the gender, have shown more impolite, than polite behaviors ( $t=-6.849 ; p=0.0001$ ). Teaching the importance of politeness to harmonize human relationships is a challenge to both educators and parents. Society should develop mechanisms to inhibit hostile behaviors, and politeness is one of those mechanisms.
\end{abstract}

Keywords: Politeness. Impoliteness. Moral behavior. Behavior observation. 


\section{Comportamentos de polidez em sala de aula}

A interação social humana constitui-se em um dos principais meios de aprendizagem dos comportamentos. A partir dela, o ser humano tem acesso às normas que regem a sociedade, internalizando-as no decorrer de seu desenvolvimento. É por meio dessas interações que os comportamentos morais ou virtudes são aprendidos e desenvolvidos. A polidez seria a porta de entrada para as virtudes e, talvez, a origem de todas.

A polidez não é propriamente uma virtude, mas tem a aparência de uma. Ela é anterior à moral, pois representa o respeito e a consideração que fazem das relações sociais mais agradáveis. Comte-Sponville (1999) retrata de forma primorosa as virtudes e inicia seu Pequeno Tratado das Grandes Virtudes expondo a importância da polidez para a aprendizagem e desenvolvimento das demais virtudes. 0 autor enfatiza que a polidez é o primeiro comportamento de boas maneiras que as crianças aprendem. Não há moral nesse ato, a criança aprende a obedecer a regras, e logo saberá diferenciar entre o que é mau (o erro) e o que faz mal (o perigo). Nessa fase é suficiente que as regras sejam estabelecidas, regras de polidez (não falar palavrão, agradecer, entre outras). A distinção entre o que é ético e estético virá progressivamente e somente mais tarde.

O indivíduo, desde a sua tenra idade, depara-se com as proibições advindas da sociedade - especialmente de pessoas significativas ao seu desenvolvimento - que vêm "moldar" seus comportamentos em prol de relações sociais que não propiciem conflitos. 0 recém-nascido não tem moral, nem pode ter; tampouco o bebê e, por um bom tempo, a criança. 0 que lhe é ensinado, bem cedo, são as proibições. "Não faça isso: é feio, é sujo, é ruim, é maldade" (Comte-Sponville, 1999, p. 15).

La Taille (2001), Talwar, Murphy e Lee (2007), entre outros, também enfatizam a importância da polidez para o bom desenvolvimento das relações sociais. A regra é, então, desprovida de outro fundamento além da convenção, de outra justificação além do uso e do respeito aos usos e costumes. É preciso cuidar, reflete Dhoquois (1993), para que a criança aprenda a respeitar regras de comportamento, tais como dizer boa noite, bom dia, obrigado, por favor, perdão, sorrir e outros, sem que, no entanto, este ensinamento a prive de sua espontaneidade, tornando-a um personagem moldado, demasiado polido.
Claybaugh (2007, p. 27) afirma que as atitudes criam hábitos e os hábitos formam o caráter e a personalidade dos indivíduos. 0 autor enfatiza, ainda, a essencialidade da prática da polidez, para o desenvolvimento relacional humano. Algumas obras possuem como intenção auxiliar o leitor na prática da polidez, considerando sua importância nas relações sociais. Em Seja Gentil, o autor apresenta algumas vantagens da gentileza e oferece elementos motivadores para que o leitor decida-se por atitudes gentis em relação a si mesmo e às demais pessoas.

A polidez por muito tempo foi confundida com hipocrisia, porém, segundo Dhoquois (1993), atualmente é tão indispensável quanto a democracia. 0 autor observa que muitos jovens modernos desqualificam a polidez, sendo vulgares, comportando-se desrespeitosamente, de forma individualista, em nome da autencidade. Confúcio (Hart, 2001) é o pensador universal da polidez e coloca, lado a lado, a sinceridade e a conveniência. 0 filósofo afirma que sempre foi e será necessário haver modos de regulação das relações humanas em sociedade.

Lucchesi-Belzane (1993, p. 28) diz que a polidez ordena eliminar a classe social entre os homens, dirigindo-se ao pobre assim como ao rico, ao passante como ao possante. Nisso, de acordo com o autor, a polidez é desinteressada, pois manifesta o puro reconhecimento do semelhante e verifica-se sob este ângulo que está mais próxima do respeito moral do que do social e convencionado.

A polidez oferece um repertório de comportamentos que podem ser insuficientes ao adulto, entretanto, para a criança são fundamentais, pois, ao dizer "por favor" ou "me desculpe", simula-se respeito e, ao dizer "obrigado", simula-se reconhecimento. É neste processo que o respeito e o reconhecimento têm início. As boas maneiras precedem as boas ações e levam a estas (Comte-Sponville, 1999, p. 17), ou seja, a polidez possui a função de preparar as crianças para o desenvolvimento de valores morais, embora elas não estejam, ainda, imbuídas de moralidade. Para Dhoquois (1993, p. 11) a polidez não tem outra pretensão senão promover uma agradável coexistência entre indivíduos chamados a viver juntos. Se a polidez afirma e pratica a igualdade entre as pessoas, o sentimento de respeito surge a partir da experiência, construindo um valor moral.

Na perspectiva de Schopenhauer (2006), a polidez é inteligência. 0 autor faz uma analogia ao afirmar que a polidez é como o calor em cera dura e 
quebradiça que se deixa moldar - pode tornar flexível e dócil o homem mais hostil. Assim, a polidez é para o homem o que o calor representa à cera. Segundo Corrêa (2003), o homem inteligente sabe calar-se, principalmente nos momentos em que o silêncio possui maior valor em comparação a quaisquer palavras.

Portanto o que primeiro importa na polidez é o respeito ao outro e não a hipocrisia cultivada. Os bons modos mostram, ao próximo, o respeito que lhe é dirigido, ou seja, ao colocar o dedo no nariz ou coçar os cabelos diante da comida, desrespeita-se a pessoa que está presente no momento. Ao deixar de visitar um colega enfermo no hospital, compreende-se não o considerar. Ao usar palavras e gestos inadequados, mesmo sem intenção, pode-se magoar pessoas e envenenar o ambiente no qual se vive. Ao ceder a vez a um homem idoso, uma mulher grávida, uma pessoa doente, demonstra-se respeito e consideração. São atitudes aprendidas por meio da educação (Lima, 2007). Neste contexto, "as boas maneiras, os bons modos, a etiqueta, a gentileza, a cortesia, a consideração, o respeito, a amabilidade, o trato social, enfim, a polidez sinaliza a boa educação".

A autora afirma, ainda, que a polidez deve se tornar um hábito e considera essencial a proposta de incluí-la como tema a ser ensinado nas escolas, porque o saber prático pode permitir o exercício da polidez no cotidiano escolar e, assim, abrir portas para outras virtudes (Lima, 2007).

Nesta perspectiva, é válido destacar que, segundo Kant (1977), "o homem só pode tornar-se homem pela educação", pois "ele é apenas o que a educação faz dele". 0 autor afirma, ainda, ser a "disciplina que primeiro transforma a animalidade em humanidade". Assim a polidez é anterior ao valor, a obediência antecede o respeito, assim como que a imitação é anterior ao dever.

La Taille (2000), por sua vez, considera a polidez um fenômeno universal que se apresenta de forma variada, em diferentes culturas. É na convivência que são criadas as formas de polidez, ou seja, são convencionadas por meio de acordos culturais.

$\mathrm{Na}$ área da justiça, pesquisadores concluíram que o tratamento impolido é percebido como violação da justiça interativa e instiga reações agressivas e ofensivas (Shapiro \& Brett, 1993). Os autores também ressaltam que, ao tratar os indivíduos polidamente, pode-se ter como retorno maior flexibilidade para a escolha de estratégias de solução de conflito e sua cooperação para resolvê-lo. Quanto a isto, ao examinar o efeito do feedback negativo na resolução de conflito, compreenderam que a recepção de críticas destrutivas são capazes de tornar as pessoas confrontadoras e/ou ampliar sua reação de esquiva.

Outra pesquisa interessante à compreensão da importância da polidez na socialização humana foi realizada por La Taille (2001) e objetivava identificar se a polidez desempenha algum papel no desenvolvimento moral infantil. Para responder a esta indagação, o pesquisador entrevistou 90 alunos de uma instituição de ensino particular, divididos em três grupos, com 30 crianças em cada um deles, de 6, 9 e 12 anos de idade. Cada grupo era formado por 15 meninos e 15 meninas. 0 método constituía-se em uma entrevista clínica com perguntas abertas e situações-problema. Os dados coletados indicaram que a maioria das crianças assimilou a boa educação associando-a ao respeito pelas regras morais e a má educação à transgressão dessas. Ou seja, as crianças compreendiam que o indivíduo com boa educação dificilmente cometeria transgressões, de modo que associavam, também, o desrespeito às regras morais a má educação. La Taille (2001, p. 113), neste contexto, afirma: "nossos dados levam a pensar que a polidez tem lugar relevante na gênese da moralidade, pois pertence ao conjunto de valores e regras com os quais a criança penetra o universo moral e sobre os quais reconstrói esse universo em direção à autonomia". Portanto a polidez para o autor é compreendida como intrínseca e posteriormente, distinguida da moral antes dos 8 ou 9 anos de idade.

Brown e Levinson (1987) estudaram a polidez do ponto de vista da linguística e não propriamente da moral. Os comportamentos que caracterizam a polidez podem ocorrer de forma verbal e não verbal. A primeira refere-se à expressão de palavras por meio da fala e escrita. A segunda relaciona-se à expressão facial, corporal e gestual do indivíduo ao seu interlocutor. Ao que se refere à manifestação não verbal, ressalta-se que algumas pesquisas sugerem que por meio de sorrisos e cumprimentos a uma distância apropriada da pessoa em contato é possível expressar a polidez e, ainda, que a compreensão e o uso de regras representadas de forma não verbal, em situações de polidez, desenvolvem-se muito cedo nas crianças.

Assim, segundo Escandell Vidal (1995), a polidez pode ser abordada sob dois enfoques: moral e 
linguístico. 0 primeiro, um enfoque tradicional, define a polidez como um conjunto de atitudes de respeito ou consideração estabelecidas nas interações dos indivíduos em seus meios, originando e estabelecendo a organização social. Essa concepção que objetiva a educação, tem a polidez como manifestação do conhecimento e propriedade dos princípios convencionais que distinguem os bons dos maus comportamentos. 0 segundo, um enfoque moderno, entende a polidez como uma conjunção de regras criadas a partir do imperativo da manutenção do equilíbrio nas interações interpessoais. Nessas regras, as manobras linguísticas se fazem presentes quando um falante as utiliza para evitar ou diminuir conflitos de interesses entre as partes.

A polidez também foi investigada por Park (2008), que analisou os efeitos a respeito da satisfação e eficiência em uma tarefa de compartilhar regras de relacionamento em grupo utilizando o comportamento polido ou eficiente como variável independente em um trabalho de grupo. 0 autor considerou a hipótese de que compartilhar as regras, atuando de forma polida ou de forma eficiente em um trabalho de grupo, poderia alterar o grau de satisfação dos participantes ao executar a tarefa, assim como alterar o seu grau de eficiência. Para tal, ele organizou, em grupos, 236 estudantes de nível médio, homens e mulheres, que tinham como tarefa montar um rádio, a partir de um kit contendo as instruções e peças. 0 autor dividiu os participantes em dois grupos: um grupo no qual todos os membros dos subgrupos, com três ou quatro participantes, recebiam igual instrução de comportar-se de forma polida ou de forma eficiente; e outro no qual metade de seus participantes recebiam instrução para se comportar de forma polida enquanto a outra metade era instruída para ser eficientes. 0 autor definiu que a forma polida incluía ter bons modos, ser cordial e respeitoso. Por este motivo, forneceu aos participantes uma instrução escrita informando que o comportamento polido incluía:

a) expressar-se de forma indireta - podendo-se, por exemplo, dizer "você poderia, por favor, me dar o transmissor" em lugar de pedir secamente "me dá o transmissor";

b) comunicar ao outro o seu erro de forma gentil e concedendo-lhe apoio - poder-se-ia, por exemplo, dizer "eu não estou certo de que você vai conseguir bom resultado por este caminho; posso ajudá-lo a encontrar melhor solução?", em substituição à frase "você fez isto errado";

c) ao pedir ajuda, garantir que não estava interrompendo ou interferindo no trabalho do outro dizendo-lhe, por exemplo, "eu sei que está ocupado, mas você poderia dar uma olhada no que estou fazendo?", sem ordenar "faça isto para mim";

d) criar relações harmoniosas, de maneira que as pessoas o considerem polido, por meio de comentários incentivadores.

Em relação à eficiência, Park (2008) a definiu como uma forma de comunicar-se diretamente, rapidamente e concisamente de maneira a obter trabalho cooperativo com os membros do grupo. Os resultados da pesquisa indicaram que ao receber a mesma instrução, a satisfação e eficiência dos participantes (comportar-se de forma polida ou comportar-se de forma eficiente) na tarefa não se alteraram, porém, quando os membros do grupo comportavam-se de forma distinta, alguns polidos e outros eficientes, houve diferença estatisticamente significativa quanto à satisfação, mas não quanto à eficiência. Ou seja, as pessoas trabalham mais satisfeitas em grupos em que as regras de relacionamento estejam previamente definidas.

Em contribuição a essa reflexão, destaca-se o estudo de Barry e Shapiro (1992) acerca de comportamentos polidos e impolidos em interação de grupo. Os comportamentos polidos propiciavam a integração do grupo (dar explicação, pedir ajuda, apresentar novas ideias, concordar com permuta de horário, compartilhar prejuízos, solicitar esclarecimento) ou apaziguamento (dar sugestões, postergar a decisão, qualificar as ideias do outro, demonstrar simpatia e/ou empatia, apoiar iniciativas, não apoiar confrontos no grupo). Os comportamentos impolidos eram de autoafirmação (autojustificar-se insistentemente, ordenar ao outro fazer algo diretamente sem lhe solicitar como favor, apresentar dúvidas de forma crítica, rejeitar a ideia do colega, discordar da opinião do outro de maneira ríspida) e hostilidade (ameaçar, criticar rispidamente, insultar, mostrar raiva). Os resultados da pesquisa de Barry e Shapiro (1992) indicaram evidência de que uma solicitação moderada obtém maior sucesso em relação ao alcance dos objetivos do que uma solicitação hostil ou direta. 
Neste contexto, é importante compreender haver influência do timbre e tonalidade da voz sobre a relação social. Para tanto, pode-se observar o estudo realizado por Laplante e Ambady (2003) que demonstrou ser a comunicação agradável capaz de facilitar e promover uma relação social amigável. Os autores utilizaram oito gravações de depoimentos que foram ouvidas por 60 alunos e 60 alunas, escolhidos randomicamente, de um curso introdutório de Psicologia. Solicitou-se aos participantes que identificassem, em seis condições disponíveis, agradável e desagradável, moderado positivamente e negativamente; qual era o nível de polidez presente nos depoimentos gravados. Em outro momento, acrescentaram-se aos depoimentos estímulos positivos "Você gostaria de tomar um sorvete?" e negativos "Você poderia deixar-me sozinho?". Concluiu-se que todas as condições em que se pretendia representar por meio do tom e timbre de voz aspectos positivos ou negativos foram percebidas pelos participantes como deveriam ser, sem erros, demonstrando a facilidade que o ser humano possui em identificar alterações de tom e timbre vocal em situações de interação social.

A polidez, portanto, não é uma virtude, mas uma qualidade apenas formal. Nenhuma virtude é natural, segundo Comte-Sponville (1993, p. 18), ninguém nasce virtuoso, pois é preciso tornar-se uma pessoa virtuosa. Comumente considerada secundária, quase insignificante ao lado das demais virtudes ou da inteligência, a polidez tem seu lugar de destaque entre os estudiosos do desenvolvimento do comportamento moral. Ela faz o homem parecer por fora como deveria ser por dentro. Assim, a polidez imita a moral.

\section{Objetivo}

Observar, registrar e comparar a frequência de comportamentos de polidez e impolidez em atividades do cotidiano de sala de aula, em alunos de ambos os sexos do ensino fundamental.

\section{Método}

Participantes: 56 alunos, 28 do sexo masculino e 28 do sexo feminino, com idade entre 10 e 16 anos.

Local: As observações foram realizadas dentro das salas de aula, durante as atividades escolares normais.
Técnica de Registro de Observação: Os pesquisadores realizaram uma visita prévia ao local para definir a melhor posição que facilitasse a observação e registro dos comportamentos selecionados e evitasse sua interferência nas atividades de sala de aula. Anterior ao início das observações, foram registrados os nomes dos participantes da pesquisa em croqui para organização do processo de observação. Seis observadores treinados coletaram os dados, em três salas de aula. As observações foram realizadas em duplas, para cálculo de fidedignidade posterior, com o uso da técnica de "Registro a intervalo de tempo" (Fagundes, 1982). Realizaram-se quatro observações, com duração de $40 \mathrm{~min}$ cada. Grupos de cinco crianças eram observados por dez minutos, de maneira que ao fim do período de observação, 60 crianças haviam sido observadas, totalizando um período de observação de 40min para cada participante.

Comportamentos de Polidez e Impolidez observados: cinco comportamentos de polidez foram selecionados - cumprimentar, agradecer, desculpar-se, pedir licença e pedir "por favor". Quando, diante de um estímulo desencadeador do comportamento de polidez, o comportamento não ocorria, a letra " $n$ " prescindia a sigla do referido comportamento. Pode-se exemplificar: uma criança deixava cair um objeto e outra o entregava; a criança que recebia o objeto sem agradecer enquanto era observada tinha seu comportamento registrado como "nag" (equivalente a "não agradecer"), considerando impolido. Os comportamentos observados são apresentados na sequência:

Cumprimentar (c): atitude de saudar outra pessoa em manifesto verbal e/ou não verbal. Os manifestos não verbais envolviam: estender a mão em direção ao outro e este realizar um movimento similar, existindo um encontro de mãos simultâneo, podendo ser aperto de mãos ou encontro entre as mãos fechadas; fazer um movimento semicircular com a(s) mão(s), apresentando a(s) palma(s) da(s) mão(s) ao campo visual de uma ou mais pessoas; fazer um gesto com uma ou as duas mãos fechadas deixando apenas o(s) polegar(es) para cima. Esses manifestos não verbais poderiam vir acompanhados ou não do manifesto verbal, tais como: "bom dia", "boa tarde", "oi", "tudo bem", “olá", "como está?", "beleza”, "e aí cara”, "e aí guri(a)", "quanto tempo" ou outras palavras e frases que expressavam cumprimento no contexto sociocultural em questão.

Agradecer (ag): manifesto verbal ou gestual, demonstrando gratidão a alguém em reconhecimento por 
algo recebido ou realizado. Os manifestos não verbais envolviam: sorriso; movimento vertical com a cabeça; fazer um gesto com uma ou as duas mãos fechadas com apenas o(s) polegar (es) para cima. Esses manifestos não verbais poderiam vir acompanhados ou não do manifesto verbal, tais como: "muito obrigado(a)", "obrigado(a)", "valeu", "é isso aí", entre outras palavras e frases que expressavam agradecimento no contexto sociocultural em questão.

Pedir licença (pl): manifesto verbal de solicitação permissiva para poder intervir no espaço de ação de outra(s) pessoa(s) e/ou manifestos não verbais que indicassem respeito ao espaço do outro quando nele havia necessidade de entrar, sair ou manipular objetos que não lhe pertencessem, bem como quando havia necessidade de expressar-se verbalmente no espaço de fala de outrem. Os comportamentos de pedir licença envolviam: solicitação de licença para poder falar, podendo ser verbal ou gestual ao levantar uma ou as duas mãos verticalmente com o dedo indicador para cima ou com a palma da(s) mão(s) exposta(s) à pessoa de autoridade no contexto escolar, objetivando ser visto por este; solicitação verbal de autorização para retirar-se de um local; entre outros comportamentos verbais e não verbais que indicassem o comportamento de pedir licença no contexto em questão.

Desculpar-se (d): ação ou efeito de desculpar-se de forma verbal e/ou não verbal caracterizado por manifesto de arrependimento por ter cometido invasão no espaço de ação de outra(s) pessoa(s). Os comportamentos verbais de pedir desculpas envolvem: solicitar verbalmente desculpas por interromper uma conversa; justificar-se por algo solicitando desculpas pelo comportamento; dizer "desculpa", "foi mal", "foi sem querer", "perdoe-me", "perdão". Os comportamentos não verbais de pedido de desculpas envolvem: fazer um movimento vertical com a cabeça; tocar na pessoa que teve seu espaço invadido apresentando expressões faciais que indiquem pedido de desculpas, como, por exemplo, levantar as extremidades nasais das sobrancelhas e sorrir. Envolvem-se, também, outros comportamentos verbais e não verbais que indicassem pedido de desculpas no contexto em questão.

Pedir por favor (pf): manifesto verbal e/ou não verbal de solicitação a uma ou mais pessoas de um ou mais comportamentos que concedam a obtenção de um bem interessante e/ou a prestação de um serviço desejado. Os comportamentos não verbais envolvem, por exemplo, tocar as palmas das mãos entre si enquanto levanta ou não as extremidades nasais das sobrancelhas. Entre os comportamentos verbais, encontram-se as palavras: "por favor", "faça-me o favor", "por gentileza", entre outros comportamentos verbais e não verbais que indicassem pedido de favor no contexto em questão.

Procedimento: Os pesquisadores procuraram a direção da escola para solicitar a autorização para a realização da pesquisa, entregando-lhes o projeto da pesquisa e o termo de autorização para ser assinado. Após a autorização da direção, os pesquisadores contataram os professores para explicar-lhes o objetivo da pesquisa, solicitar-lhes que assinassem o Termo de Consentimento Livre e Esclarecido e, após a anuência dos mesmos, agendar o início das observações. A apresentação dos pesquisadores aos alunos antecedeu o início das observações e, nesta ocasião, foi explicitado aos alunos que se tratava de uma pesquisa de observação sem interferências no processo de ensino-aprendizagem. Convém ressaltar que, durante a apresentação, não foram realizadas referências diretas ao comportamento observado, ou seja, à polidez. Pois, neste caso, se o objetivo completo fosse formulado, poder-se-ia desencadear uma alteração das respostas naturais dos participantes. Usou-se, portanto, uma técnica denominada "engodo" (Cozby, 2003), na qual o real objetivo da pesquisa não é esclarecido no momento da coleta de dados para evitar interferências à situação natural que se deseja estudar. 0 objetivo da pesquisa foi revelado ao término da coleta de dados.

\section{Resultados}

Inicialmente foram selecionados 60 alunos, porém dois foram eliminados da amostra por faltarem a mais da metade das observações. A amostra final compôs-se, então, por 28 meninos (com idade média $=12,10$ ) e 28 meninas (com idade média $=12,21)$, que estudavam na $5^{\underline{a}}$ e $6^{\underline{a}}$ séries do ensino fundamental.

A frequência absoluta dos comportamentos de polidez e impolidez observados (agradecer, cumprimentar, pedir licença, pedir "por favor" e desculpar-se), para ambos os sexos pode ser conferida na 
Tabela 1. Observou-se uma prevalência dos comportamentos impolidos em relação aos polidos em três categorias (agradecer, pedir "por favor" e desculpar-se) para ambos os sexos enquanto para o sexo masculino houve a prevalência, também, do comportamento de pedir desculpas. 0 comportamento de "pedir licença" ( $n=9)$ teve maior frequência entre as meninas quando comparado com "não pedir licença” ( $\mathrm{n}=8)$. Por sua vez, o comportamento de "cumprimentar" apareceu unicamente na categoria polidez, pois a sua ocorrência foi observada quando os alunos entravam na sala e depois desta situação, não mais havia oportunidade para que fosse observado.

Os comportamentos de polidez e impolidez entre os alunos do sexo masculino e feminino foram comparados utilizando-se o Teste $t$ (de student), que apresentou não haver diferenças estatisticamente significativas entre os grupos tanto para polidez $(\mathrm{t}=1,113 ; \mathrm{p}=0,271)$ quanto para impoli$\operatorname{dez}(t=1,206 ; p=0,233)$. Porém ao se comparar a frequência total dos comportamentos de polidez com os de impolidez, o Teste $t$ demonstrou haver diferenças estatisticamente significativas, posição de $1 \%(\mathrm{t}=-6,849 ; \mathrm{p}=0,0001)$, entre as variáveis. Esses resultados significam que foram registrados muito mais comportamentos de impolidez em relação aos de polidez entre os alunos observados, independentemente do sexo.

A Gráfico 1 apresenta a comparação do percentual de comportamentos de polidez e impolidez observados entre os alunos. É surpreendente verificar que, para ambos os sexos, o padrão de comportamento expresso pelos alunos é o de maus modos.
Agrupando-se os dados femininos e masculinos tem-se que $78,48 \%$ dos comportamentos observados foram de impolidez enquanto apenas $21,51 \%$ de comportamentos polidos.

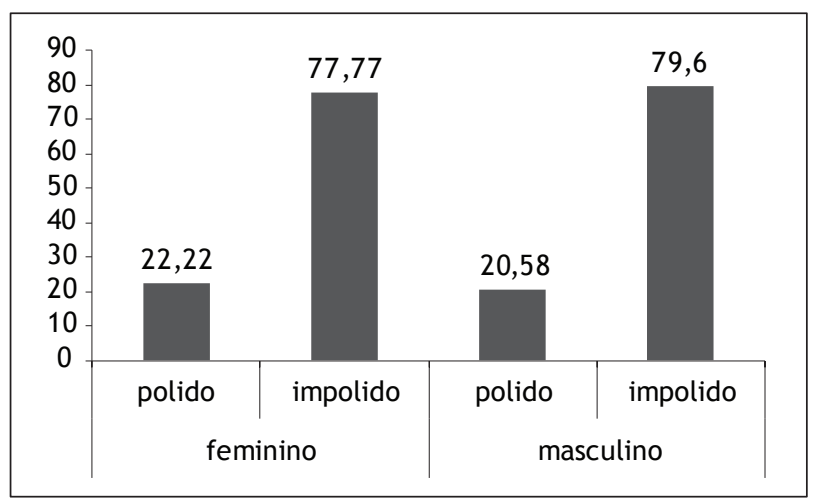

Gráfico 1 - Percentagem de comportamentos polidos e impolidos em função do sexo dos participantes

Fonte: Dados da pesquisa.

Os Gráficos 2 e 3, na sequência, apresentam os dados comparativos, por participante, em função do sexo, dos comportamentos de polidez e impolidez observados. Pode-se ver em ambas as Figuras ser raro os alunos com mais comportamentos polidos, em detrimento dos impolidos. Entre as meninas, apenas duas (as participantes 12 e 14) têm maior frequência de comportamentos polidos e entre os meninos, apenas os participantes 9 e 27, invertem a tendência do grupo de participantes observados apresentando uma frequência maior de polidez em comparação à impolidez.

Tabela 1 - Frequência dos comportamentos polidos e impolidos dos participantes

\begin{tabular}{llll|lll}
\hline & \multicolumn{3}{c|}{ Feminino } & \multicolumn{3}{c}{ Masculino } \\
\hline & polido & impolido & total & polido & impolido & total \\
Agradecer & 4 & 50 & 54 & 2 & 44 & 46 \\
Cumprimentar & 15 & 0 & 15 & 16 & 0 & 16 \\
Pedir licença & 9 & 8 & 17 & 2 & 4 & 6 \\
Pedir "por favor" & 2 & 18 & 20 & 1 & 10 & 11 \\
Desculpar-se & 0 & 29 & 29 & 0 & 23 & 23 \\
\hline Total & 30 & 105 & 135 & 21 & 81 & 102 \\
\hline
\end{tabular}

Fonte: Dados da pesquisa. 


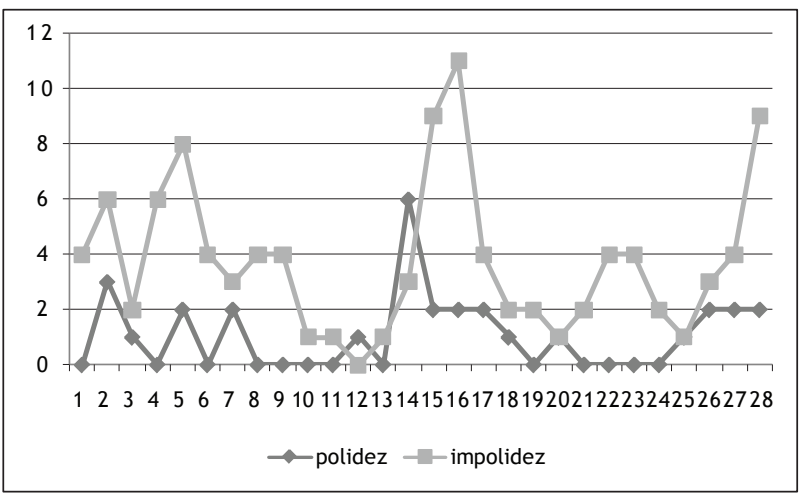

Gráfico 2 - Comparação dos comportamentos de polidez e de impolidez entre os participantes do sexo feminino

Fonte: Dados da pesquisa.

Entretanto é válido ressaltar que, entre as meninas, houve três participantes $(5,16$ e 28$)$ com graus muito altos de comportamentos impolidos, enquanto as demais participantes $(8,9,10,11,13,19,21$, $22,23,24)$, totalizando 10 meninas, não apresentaram um único comportamento polido. Entre os meninos, verificou-se que 11 deles $(2,3,4,14,16$, $19,21,22,25$ e 28) não apresentaram sequer um comportamento polido e os participantes 4,21 e 26 tiveram uma frequência muito alta de comportamentos impolidos.

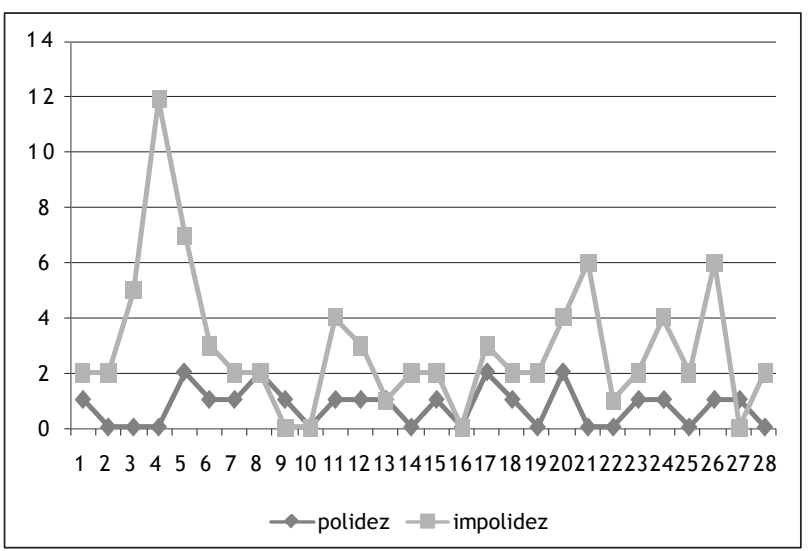

Figura 3 - Comparação dos comportamentos de polidez e impolidez entre os participantes do sexo masculino

Fonte: Dados da pesquisa.

Durante os períodos de observação alguns comportamentos de relacionamento aluno-professor referentes à polidez atraíram os observadores. Pode-se exemplificar:
Em uma determinada ocasião, um aluno pegou uma caneta no interior do estojo de um colega, sem pedir. $O$ participante sob observação chamou a professora e a informou sobre o comportamento do colega. A professora respondeu ao reclamante que deveria emprestar a caneta. Não considerou a invasão do espaço pessoal do aluno reclamante. $O$ colega, que pegou a caneta sorriu.

Vê-se que o modelo fornecido pelo professor é de reforçar a impolidez. Neste sentido, o não exercício da polidez incentivado pelo professor, enfraquece a emissão do comportamento pelos alunos que tentam apresentá-lo e incentivam os comportamentos de impolidez dos demais.

Alguns comportamentos das professoras causavam efeito imediato e intenso para os alunos. Por exemplo, foi possível observar que, ao responder ao cumprimento da professora, os alunos agiam de forma calorosa. No entanto, nos momentos em que a professora adentrava na sala de aula e não cumprimentava seus alunos, os mesmos também não o faziam. 0 excesso de conversas paralelas durante as aulas facilitava a ocorrência de comportamentos impolidos, pois não pedir licença para ir ao banheiro, levar papel ao lixeiro ou apontar o lápis passou a ser atitude normal durante a aula.

Registros adicionais indicaram alunos que solicitavam gestualmente licença para falar, com a mão levantada por exemplo, sem serem notados, enquanto aqueles que interrompiam o discurso pedagógico recebiam atenção. Alguns alunos levantavam a mão para pedir licença para falar, esperavam um pouco e, em seguida, por não serem atendidos, movimentavam-se livremente pela sala e interrompiam a explanação da professora. Em momentos em que os alunos realizavam pequenas tarefas para a professora, tais como apagar o quadro ou alcançar-lhe algum objeto, em geral, não recebiam agradecimento. E, por outro lado, em certa ocasião, uma professora distribuiu os livros aos alunos que também não lhe agradeceram. Nas poucas manifestações de polidez dos alunos, não houve acolhimento por parte das professoras, ocorrendo também, em proporção menor, o inverso.

\section{Discussão}

Pesquisadores e educadores brasileiros têm se debruçado a respeito do quê e como ensinar o comporta- 
mento moral para alunos na escola (Durkheim, 2007; Bicudo, 1982; Dias, 2005; Araujo, 2000). Viu-se nesta pesquisa que os alunos apresentaram significativamente menos comportamentos polidos em comparação aos impolidos ( $\mathrm{t}=-6,849 ; \mathrm{p}=0,0001)$. Afora isto, os poucos comportamentos polidos apresentados não foram reforçados pelos professores, que agiam, inclusive, no sentido de desqualificar a polidez.

Dias (2005) aponta para a necessidade de introdução do tema educação de valores com vistas à melhoria da sociedade marcada pela racionalização e tecnificação das relações sociais, ou seja, é preciso construir novos valores educativos pautados na solidariedade e na cooperação, em contraposição ao individualismo. Os dados desta pesquisa indicaram que os professores não se comportam de forma polida, de maneira que na escola, onde passam horas significativas de seu dia, os estudantes aprendem comportamentos impolidos em contraposição com aqueles que melhor facilitariam relacionamentos agradáveis e virtuosos.

Para Araújo (2000), um dos objetivos da educação é o da formação ética. 0 autor propõe ações intencionais para que a escola propicie aos sujeitos da educação os instrumentos necessários à construção de suas competências cognitivas, afetivas, culturais e orgânicas, dando-lhes condições de agir moralmente no mundo. Ele sugere que os valores a serem estudados na escola sejam os definidos como valores universalmente desejáveis, isto é, a justiça, a igualdade, a equidade e a participação coletiva na vida pública e política de todos os membros da sociedade.

A educação moral, segundo Bicudo (1982), pode ser um processo de transmissão cultural, por meio do qual o indivíduo introjeta hábitos, costumes, normas e regras culturais aceitas pelo grupo, como também um processo que auxilia a pessoa a discernir e esclarecer os valores que lhes são significativos, condicionando suas decisões morais às circunstâncias ou situações vividas em contextos específicos.

Pesquisas futuras acerca de polidez necessitam incluir o relacionamento entre pais e filhos, de várias idades e também registrar sistematicamente o relacionamento professor-aluno. Além disso, os estudiosos do comportamento moral devem desenvolver programas de educação moral a ser realizado na escola (Gomide, no prelo). A educação moral sem dúvida é o principal antídoto ao comportamento violento da sociedade. Investir em pesquisas e tratamento das consequências da violência social e familiar é tão importante quanto enfrentar o desafio de criar condições favoráveis ao desenvolvimento das virtudes, considerando a polidez como início de todas elas.

\section{Referências}

Araújo, U. (2000). Escola, democracia e a construção de personalidades morais. Educação e Pesquisa, 26(2), 91-107.

Barry, B., \& Shapiro, D. L. (1992). Influence tatics in combination: The interactive effects of soft versus hard tactics and rational exchange. Journal of Applied Social Psychology, 22, 1429-1441.

Bicudo, M. A. (1982). Fundamentos éticos da educação. São Paulo: Autores Associados; Cortez.

Bronw, P., \& Levinson, S. C. (1987). Politeness: Some universals in language usage. London: Cambridge University Press.

Claybaugh, W. (2007). Seja gentil. São Paulo: Gente.

Comte-Sponville, A. (1993). A pequena virtude. In R. Dhoquois. A Polidez: Virtude das aparências. Porto Alegre: LP\&M.

Comte-Sponville A. (1999). Pequeno tratado das grandes virtudes. São Paulo: M. Fontes.

Corrêa, E. G. (2003). 0 homem inteligente (Cartas).

Cozby, P. C. (2003). Métodos de pesquisa em ciências do comportamento. São Paulo: Atlas.

Dias, A. A. (2005). Educação moral e autonomia a educação infantil: 0 que pensam os professores. Psicologia: Reflexão e Crítica, 18(3), 370-380.

Dhoquois, R. (Org.). (1993). Prefácio: Pequenas e grandes virtudes. In R. Dhoquois. A Polidez: Virtude das aparências. Porto Alegre: LP\&M.

Durkheim, E. (2007). 0 ensino da moral na escola primária. Novos Estudos - CEBRAP, (78), 59-75. Recuperado em 20 mar. 2011, em http://dx.doi.org/10.1590/ S0101-33002007000200008

Escandell Vidal, M. V. (1995). Cortesía, fórmulas convencionales y estrategias indirectas. Revista Español de Linguística, 25(1), 31-66. 
Fagundes, A. J. F. M. (1982). Descrição, definição e registro de comportamento. São Paulo: Edicon.

Gomide, P. I. C. (Org.). (no prelo). Comportamento moral: Uma proposta para o desenvolvimento das virtudes. Curitiba: Juruá.

Kant, E. (1977). Crítica da razão pura. Lisboa: Fundação Calouste Gulbenkian.

Hart, M. H. (2001). As 100 maiores personalidades da história. Rio de Janeiro: Difel.

La Taille, Y. (2000). Para um estudo psicológico das virtudes morais. Educação Pesquisa, 26(2), 109-121. Recuperado em 20 mar. 2011, em http://dx.doi.org/ 10.1590/S1517-97022000000200008

La Taille, Y. de (2001). Desenvolvimento moral: A polidez segundo as crianças. Cadernos de Pesquisa, (114), 89-119.

Laplante, D., \& Ambady, N. (2003). On how things are said: Voice tone, voice intensity, verbal content, and perceptions of politeness. Journal of Language and Social Psychology, 22(4), 434-441. Recuperado em 20 mar. 2011, em doi: 10.1177/0261927X03258084

Lima, R. de. (2007). A polidez e a cultura da escola em tempos sombrios. Revista Espaço Acadêmico, 6(69). Recuperado em 20 mar. 2010, em http://www. espacoacademico.com.br/069/69lima.htm
Lucchesi-Belzane, M. (1993). Um vazio essencial. In R. Dhoquois. A Polidez: Virtude das aparências (pp. 23-38). Porto Alegre: LP\&M.

Park, H. S. (2008). The effects of shared cognition on group satisfaction and performance: politeness and efficiency in group intertiction. Journal of Adolescence, 20, 393-402.

Pedlow, R., Wales, R. E., \& Sanson, A. (2001). Children's production and comprhension of politeness in requests: Relationship to behavioral adjustment in midddle childhood. Journal of Language and Social Psychology, 24(3), 347-367. Recuperado em 20 mar. 2011, em doi: 10.1177/0142723704046188

Talwar, V., Murphy, S. M., \& Lee, K. (2007). White lie-telling in children for politeness purposes. International Journal of Bhavioral Development, 31(1), 1-11.

Schopenhauer, A. (2006). Aforismos para a sabedoria de vida. São Paulo: M. Fontes.

Shapiro, D. L., \& Brett, J. M. (1993). Comparing tree processes underlying judgements of procedural justice: A filed study of mediation and arbitration. Journal of Personality and Social Psychology, 65(6), 11671177. Recuperado em 20 mar. 2011, em doi: 10.1037/ 0022-3514.65.6.1167 